\title{
Performance Analysis of ZigBee Protocol in Smart Dust Communication Network
}

\author{
Sandeep Kumar \\ Department of Computer Science and Engineering \\ Thapar University, India.
}

\begin{abstract}
Smart Dust is the network of small devices (also called as Sensor Nodes) with many electronic components such as memory, CPU, radio and sensor and each of these components consumes power. Sensor nodes have a battery and can work only as long as the battery lasts. In other words, it is very important to optimize every computation in order to increase the sensor's lifetime. To achieve this, an energy efficient protocol called as ZigBee protocol is analyzed. Analysis is done using two different topologies (Random and Clustered Topology). Both topologies are properly analyzed in terms of number of nodes and in terms of number of nodes/cluster respectively. Parameters used for analysis are Total Packets Transmitted, Total Packet Loss, Packet Loss Rate and Bit Rate.
\end{abstract}

\section{Keywords}

Smart Dust, Random Topology, Clustered Topology, ZigBee Protocol

\section{INTRODUCTION}

Smart Dust is comprised of a vast number of ultra-small fully autonomous computing, communication and sensing devices. It has very restricted energy and computing capabilities that co-operate to accomplish a large sensing task. Smart Dust sensing devices are capable of gathering many types of information from the environment including temperature, light, humidity and vibrations [1]. Such devices exchange information with either to other nodes or to the outside world without being physically connected to another device. These sensor networks are very different from traditional networks since sensor nodes (SNs) are very small devices with many electronic components such as memory, CPU, radio and sensor and each of these components consumes power. SNs have a battery and can work only as long as the battery lasts[2]. In other words, it is very important to optimize every computation in order to increase the sensor's lifetime.

This paper presents performance analysis of ZigBee Protocol using Random and Clustered topology. Analysis is done on the basis of scalability in the network in terms of number of nodes and number of nodes/cluster.

\section{ZIGBEE PROTOCOL}

ZigBee protocol is one most valuable protocol used in small area network to provide reliable packet delivery. The main objective of the protocol is to have low power consumption and cost efficient wireless network [3]. ZigBee provides the efficiency to work on different kind of devices that are being used for different purpose and for different volumes. ZigBee protocol requires low energy and work in small network area with limited resources; because of this the network topology is another main constraint to decide the effectiveness of the

\author{
V. P. Singh \\ Department of Computer Science and Engineering \\ Thapar University, India.
}

protocol. Most common topologies used in such network are Star topology, Tree topology and Mesh topology.

The network supported by the ZigBee protocol is basically a Personal Area Network (PAN) or the Home area network. It is basically the small area network represented by some campus, medical area, research center or the home area. ZigBee protocol is also used in a wireless sensor network with some constraint specification in terms of size, distance etc. Each sub network in the PAN area is identified by a PAN id. The PAN id is a 16 bit id which identifies the network. A network can have number of sub-networks that are controlled by separate coordinators. When the network coordinator chooses the PAN id it should not be used by any other sub network. ZigBee protocol uses the network of smart sensors that area having their own processing unit, memory unit and the control unit. Because of this, these kinds of networks are very much dependent on the devices to perform the smart decision and the communication. The use of ZigBee protocol is also growing in some other areas such as body area network with wearable components.

\section{PERFORMANCE ANALYSIS}

In this section, First simulation setup is described. Then Analysis of simulation results is reported.

\subsection{Simulation description}

Simulation is done using NS-2 tool. Ns-2 is a discrete event simulator targeted at networking research. It provides substantial support for simulation of TCP, routing and multicast protocols over wired and wireless networks. The system is implemented on Ubuntu Environment with NS-2 simulator and XGraph is used as the tool for graph analysis. Configuration of network is shown in Table 1 .

Table 1: Topological architecture

\begin{tabular}{|c|c|}
\hline Parameter & Value \\
\hline Number of Nodes & $15,25,50,75$ \\
\hline Topography Dimension & $670 \mathrm{~m}$ x $670 \mathrm{~m}$ \\
\hline Traffic Type & CBR \\
\hline Radio Propagation Model & Two-Ray Ground Model \\
\hline MAC Type & 802.15 .4 .Mac Layer \\
\hline Packet Size & 512 bytes \\
\hline Mobility Model & Random Way Point \\
\hline Antenna Type & Omni directional \\
\hline Protocol & ZigBee \\
\hline Topology & Random, Clustered \\
\hline Number of Clusters & Single,Multiple \\
\hline
\end{tabular}

\subsection{Simulation Scenarios}

In this analysis, the ZigBee protocol is implemented using two different topologies as explained below: 


\subsubsection{Random Topology}

In this type of topology, a node sends request in its network for data communication. Any nodes free in network and nearest to the sender node, responds to the request by accepting the request and sending the acknowledgment for further communication. As, sender node receives the acknowledgment it start communication. So, in random topology, by broadcasting the requesting message, communication among nodes in a network takes place easily. In random topology, nodes are scattered over the given area randomly as shown in figure 1 . Circles represent broadcasting area of the nodes.

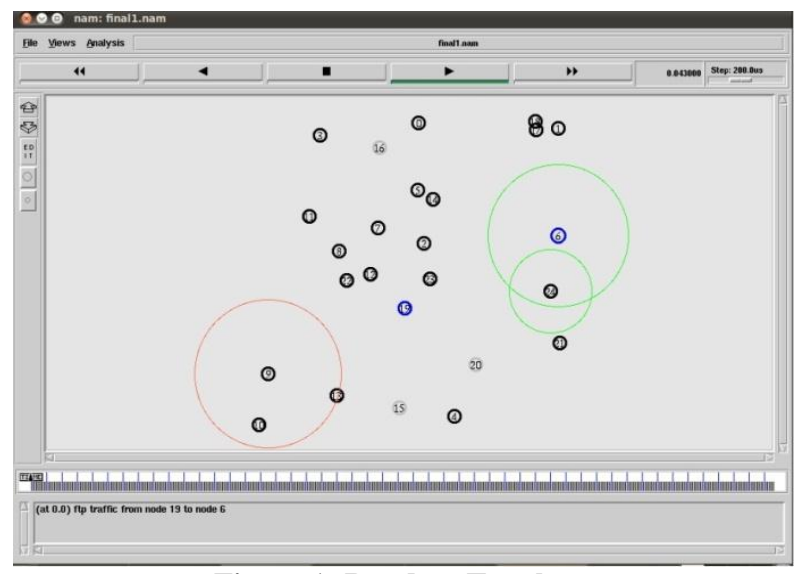

Figure 1: Random Topology

\subsubsection{Clustered Topology}

In Clustered topology, nodes are divided into groups or clusters and each cluster has its own cluster head or coordinator. All nodes of each group send information to its cluster head and only cluster head can pass information to another cluster head. This process goes on until it reaches the destination.

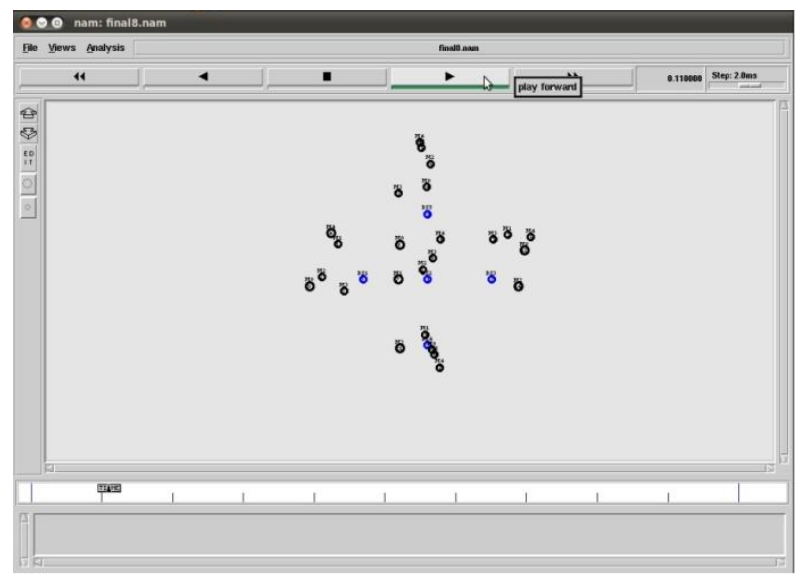

Figure 2: Clustered Topology

In clustered topology, network is divided into clusters and each cluster has its own cluster head or coordinator. Network of 30 nodes is there as shown in figure 2. Cluster consists of 6 nodes and there is total number of 5 clusters.

\section{RESULTS}

Complete analysis is divided into two parts. In first part, analysis of ZigBee protocol is done over Smart Dust network using Random topology and in second part, analysis of ZigBee protocol is done using Clustered topology.

\subsection{Performance Analysis Results}

In this analysis, four different Scenarios are taken in terms of Number of nodes, all other parameters are identical. The particular work is showing the difference in terms of scalability. To analyze the effect of scalability, Xgraph is used. The parameters taken for the comparison are

- Number of Packet Transmitted

- Number of Packets Lost

- Bit Rate

- Packet Loss Rate

\subsubsection{Random Topology Analysis}

In all graphs of random topology, 4 scenarios are taken which are different in number of nodes and rest of parameters is same in all scenarios.

- Yellow line represents Network of 75 nodes

- Red line represents Network of 50 nodes

- Blue line represents network of 25 nodes

- Green line represents network of 10 nodes

- $\mathrm{X}$-axis represents time and $\mathrm{Y}$-axis represents parameter.

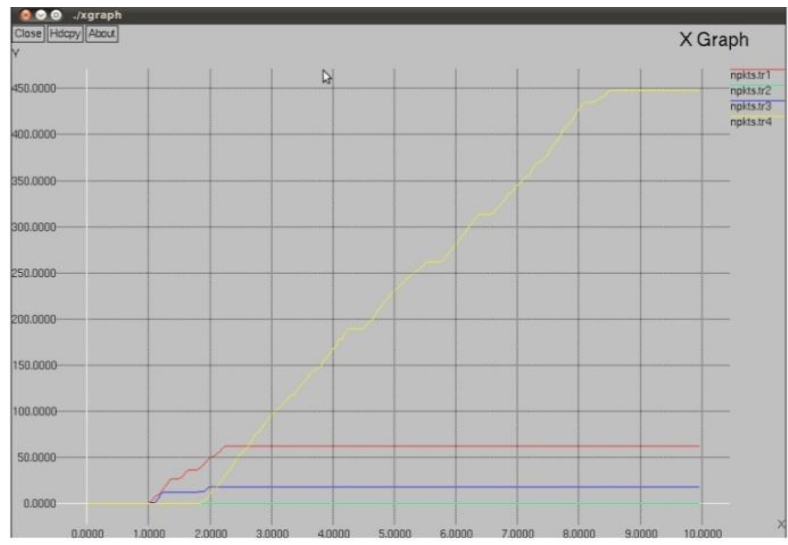

Figure 3: Number of packets Transmitted (Random Topology)

As the number of nodes in the network increases, the distance between the nodes decreases. As the distance between nodes in a network decreases, number of packet transmitted increases as shown in figure 3.

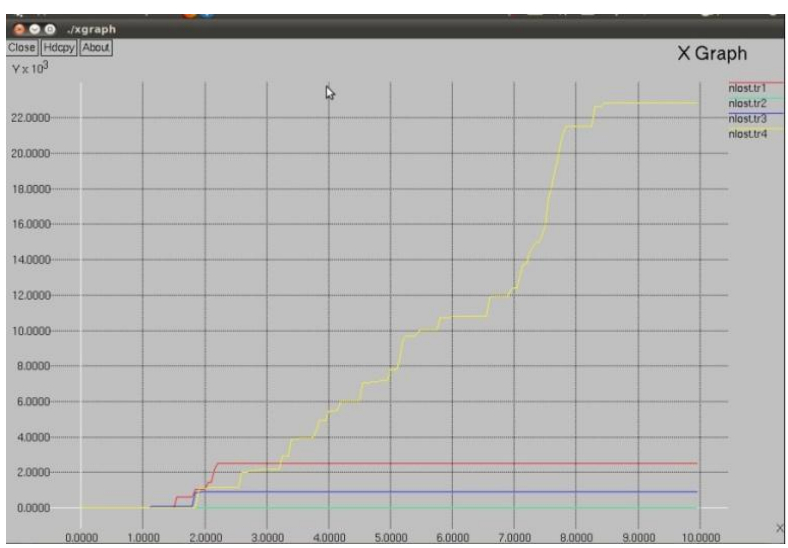

Figure 4: Number of packets loss (Random Topology)

As the number of nodes in the network increases, the distance between the nodes decreases. Because of this there are more chances of collision. As the collision rate increased the data loss is also increased as shown in figure 4 . 


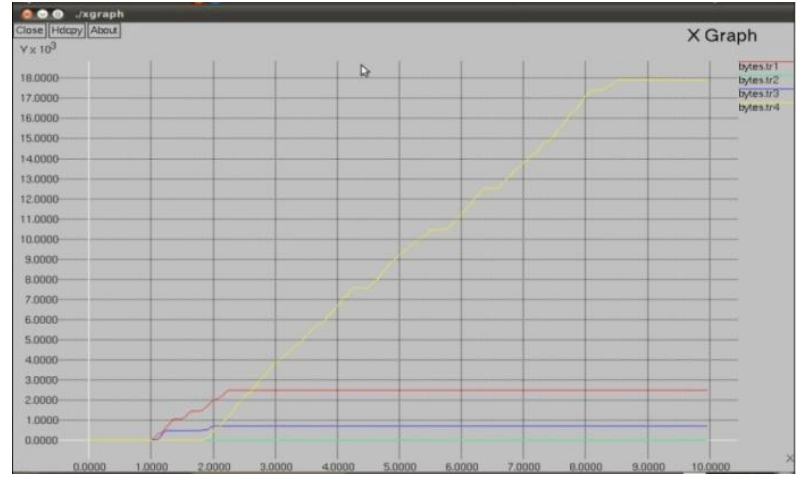

Figure 5: Bit Rate (Random Topology)

As the number of nodes in the network increases, the distance between the nodes decreases which significantly increases the Communication rate or bit rate as shown in figure 5.

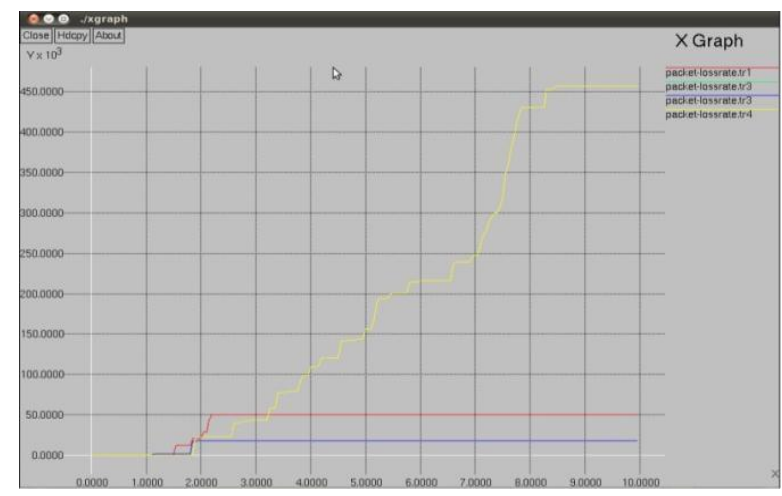

Figure 6: Packet Loss Rate (Random Topology)

As the number of nodes in the network increases, the collision rate between nodes in a network increases which further increases Packet loss rate as shown in figure 6. Performance analysis results of ZigBee protocol using random topology is shown in Table 2.

Table 2: Analysis of Smart Dust Network using Random Topology

\begin{tabular}{|c|c|c|c|c|}
\hline $\begin{array}{c}\text { No. of } \\
\text { nodes }\end{array}$ & (15) & (25) & (50) & (75) \\
\hline $\begin{array}{c}\text { Number of } \\
\text { Packet } \\
\text { Transmitted }\end{array}$ & Less & Medium & High & $\begin{array}{c}\text { Very } \\
\text { High }\end{array}$ \\
\hline $\begin{array}{c}\text { Number of } \\
\text { Packet Lost }\end{array}$ & Less & Less & Medium & High \\
\hline $\begin{array}{c}\text { Packet Loss } \\
\text { Rate }\end{array}$ & Low & Low & High & High \\
\hline Bit Rate & Less & Medium & High & $\begin{array}{c}\text { Very } \\
\text { High }\end{array}$ \\
\hline
\end{tabular}

\subsubsection{Clustered Topology Analysis}

In all graphs of clustered topology, 2 scenarios are taken which are different in number of nodes/cluster and rest of parameters is same in all scenarios.

- Red line represents Network of 30 nodes(6 nodes/cluster)

- Green line represents network of $50 \operatorname{nodes}(10$ nodes/cluster)

- $\mathrm{X}$-axis represents time and $\mathrm{Y}$-axis represents parameter.

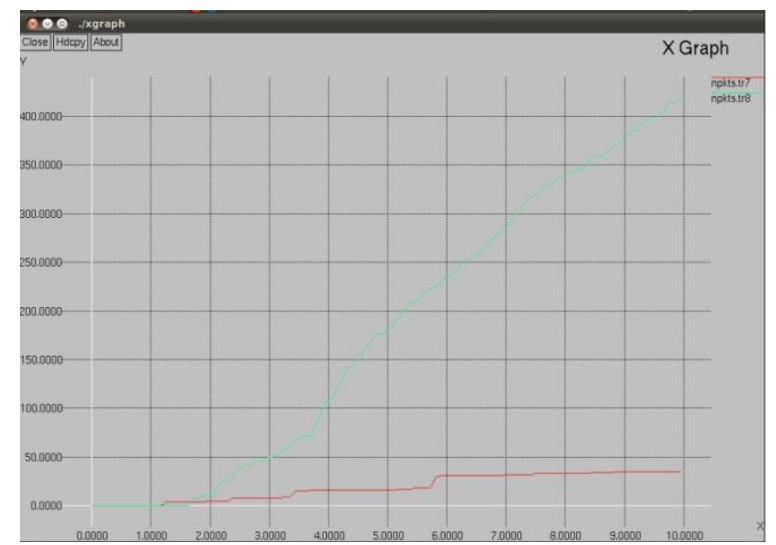

Figure 7: Number of Packets Transmitted (Clustered Topology)

In dense clustered network, more communication is performed between nodes and it increases the total packets transmitted over the network as shown in figure 7.

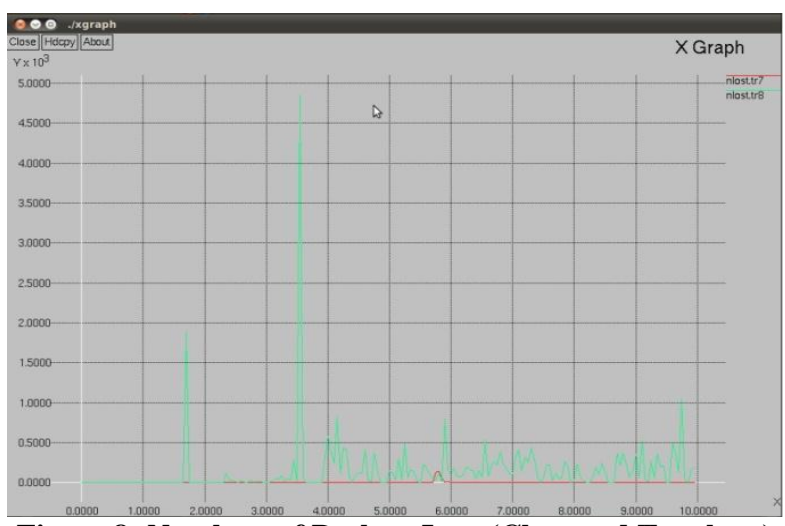

Figure 8: Numbers of Packets Lost (Clustered Topology)

In a clustered network as the inter cluster communication is increased the load on coordinator node increase, it results more packet loss as shown in figure 8 .

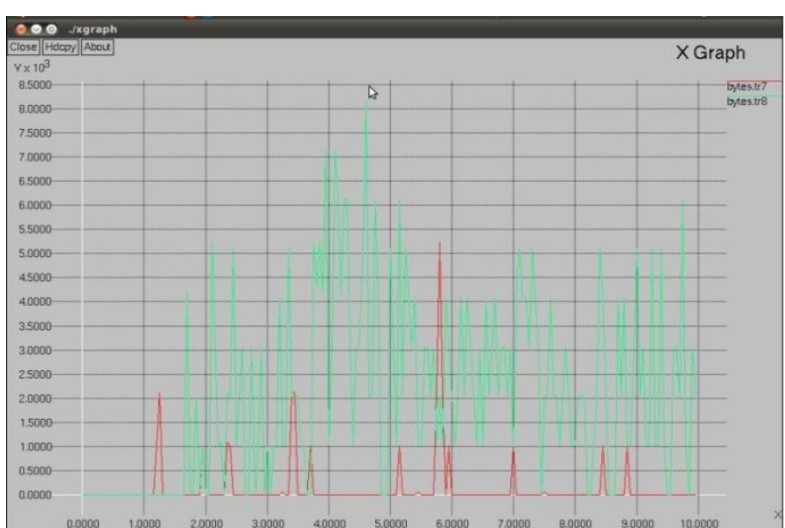

Figure 9: Bit rate (Clustered Topology) 
As the number of nodes in network increases, communication between nodes also increases, which significantly increases bit rate as shown in figure 9 .

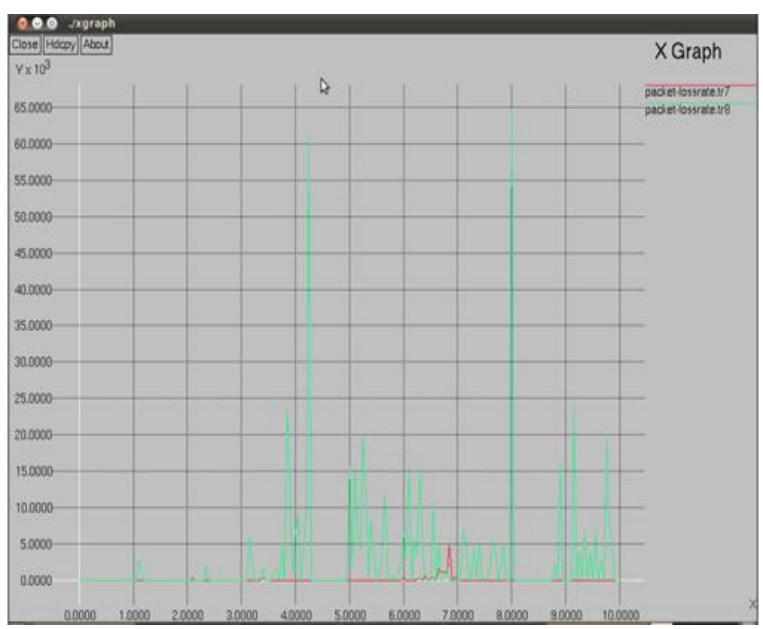

Figure 10: Packet Loss Rate (Clustered Topology)

More the communication between inter cluster nodes, more the congestion on centralized nodes. It increases the loss rate over the network as shown in figure 10. Analysis results are shown in Table 3.

Table 3: Analysis of Smart Dust Network using Clustered Topology

\begin{tabular}{|c|c|c|}
\hline $\begin{array}{c}\text { Number of } \\
\text { Nodes }\end{array}$ & $\mathbf{3 0}$ & $\mathbf{5 0}$ \\
\hline $\begin{array}{c}\text { Number of } \\
\text { Packet } \\
\text { Transmitted }\end{array}$ & Low & High \\
\hline $\begin{array}{c}\text { Number of } \\
\text { Packet Lost }\end{array}$ & Low & High \\
\hline $\begin{array}{c}\text { Packet Loss } \\
\text { Rate }\end{array}$ & Low & High \\
\hline Bit Rate & Low & High \\
\hline
\end{tabular}

\section{CONCLUSION}

In Smart Dust network, there are different routing protocols all of which have their own specifications and benefits. For the very small sensor network we always look for the minimum energy consumed networks. In this presented research work, Analysis of ZigBee protocol has been done in Smart Dust network using 6 different scenarios. These scenarios are different in terms of number of nodes and number of nodes/cluster. Complete work is analyzed and implemented on two different topologies. The simulation is performed in NS-2 environment. Result of analysis proves that as the number of nodes in a network increases; it increases the number of packets transmitted as well as number of packets loss over the network. In case of clustered network, higher the number of nodes/cluster; higher number of packets transmitted as well as Packet loss rate. In this research work,
Analysis based upon different kind of network scenarios under different parameters using ZigBee protocol has been done. Limitations of ZigBee protocol in terms of scalability are also shown in results. So, in future, work can be extended to design a new protocol that can cover all or some of these drawbacks.

\section{REFERENCES}

[1] I.F. Akyildiz, Weilian Su, Sankara subramaniam, E. Cayirci, "A survey on sensor networks", IEEE Communications Magazine, Aug 2002, pp 392-422.

[2] K.S.J. Pister, J.M. Kahn and B.E. Boser, "Smart Dust: Wireless networks of milli-meter scale sensor nodes", Electronics Research Laboratory Research Summary, July, 1999.

[3] Z. Alliance,"ZigBee Specifiications", $1^{\text {st }}$ ed. ZigBee Standard Organization, http://www.ZigBee.org. ,June 2005.

[4] Ioannis Chatzigiannakis, Athanassios Kinalis, Sotiris Nikoletseas, "Power Cons-ervation Schemes for Energy Efficient Data Propagation in Heterogeneous Wireless Sensor Networks", Sept. 2004.

[5] Azzedine Boukerche, Ioannis Chatzigiannakis, Sotiris Nikoletseas, "Power-Efficient Data Propagation Protocols for Wireless Sensor Networks", February 28, 2005.

[6] Thanasis Antoniou, Azzedine Boukerche, Ioannis Chatzigiannakis, George Mylonas, Sotiris Nikoletseas, "A New Energy Efficient and Fault-tolerant Protocol for Data Propagation in Smart Dust Networks using Varying Transmission Range", 37th Annual ACM/IEEE Simulation Symposium, pp. 43-52 July 15, 2005.

[7] W.R. Heinzelman, A. Chandrakasan, H. Balakrishnan, "Energy-efficient communica-tion protocol for wireless micro-sensor networks", IEEE Hawaii International Conference on System Sciences, Aug 2000.

[8] A. Perrig, R. Szewczyk, J.D. Tygar, V. Wen, and D. Culler, "SPINS: Security protocols for sensor networks", Wireless networks 8,521-534,2002, Kluwer Academic Publications, June, 2002.

[9] I. Chatzigiannakis and S. Nikoletseas, "A sleep-awake protocol for information propagation in smart dust networks",3rd International Workshop on Mobile, Adhoc and Sensor Networks (WMAN 2003), 2003, IPDPS Workshops, pp 225.

[10] S.S.Riaz Ahamed," The Role Of ZigBee Technology In Future Data Communication System", Journal of Theoretical and Applied Information Technology () 2005 - 2009 JATIT

[11] V.S.Hsu, J.M.Kahn, K.S.J.Pistcr, "Wireless Communications for Smart Dust", UC Berkeley Electronics Research Laboratory Memorarzdupn, Jan. 2006.

[12] L. Doherty, B. A. Warneke, B. E. Boser, and K. S. J. Pister, "Energy and performance considerations for Smart Dust,” Int. J. Parallel Distrib. Syst. Networks, vol. 4, no. 3, pp. 121-133, 2001.

[13] L. Doherty, B. A. Warneke, B. E. Boser, and K. S. J. Pister, "Energy and performance considerations for 
Smart Dust,” Int. J. Parallel Distrib. Syst. Networks, vol. 4, no. 3, pp. 121-133, 2001.

[14] Meng-Shiuan Pan," Quick Convergecast in ZigBee Beacon-Enabled Tree-Based Wireless Sensor Networks". Journal Computer Communications archive Volume 31 Issue 5, March, 2008 Pages 999-1011.

[15] Steffen Peter, Krzysztof Piotrowski," Public key cryptography empowered smart dust is affordable". International Journal of Sensor Networks, Vol. 4, No. $1 / 2$. (2008)
[16] Li-Chien Huang," A ZigBee-based monitoring and protection system for building electrical safety". Energy and Buildings Volume 43, Issue 6, June 2011, Pages $1418-1426$

[17] Sinem Coleri Ergen," ZigBee/IEEE 802.15.4 Summary", September 10, 2004. 